\title{
El ASPO y el acceso online a lo culltural-artístico
}

\author{
O Isolamento Social Preventivo e Obrigatório e o acesso \\ online às obras artístico-culturais [Quarentena e o acesso \\ online às obras artístico-culturais]
}

\author{
The Preventive and Compulsory Social Isolation and online \\ access to cultural-artistic works [Quarantine and online access \\ to cultural-artistic works]
}

\author{
Racioppe, Bianca
}

Bianca Racioppe

bianca_racioppe@yahoo.com.ar

Universidad Nacional de La Plata, Argentina

REVCOM. Revista científica de la red de carreras de Comunicación Social

Universidad Nacional de La Plata, Argentina

ISSN: 2451-7836

Periodicidad: Bianual

núm. 11, 2020

redcom.revcom@gmail.com

Recepción: 01 Diciembre 2020

Aprobación: 02 Diciembre 2020

URL: http://portal.amelica.org/ameli/

jatsRepo/203/2031709010/index.html

DOI: https://doi.org/10.24215/24517836e041
Resumen: El artículo reflexiona acerca del acceso a contenidos culturales-artísticos durante el Aislamiento Social Preventivo y Obligatorio (ASPO) dispuesto como estrategia para disminuir la propagación del virus Covid-19. Se identifican, describen y contraponen las estrategias que llevaron adelante algunas plataformas comerciales de distribución de contenidos por Internet y las organizaciones culturales dependientes del Estado. Por último, se analizan dos experiencias artísticas en las que las arquitecturas de las plataformas digitales que habilitan la transmisión del evento se vuelven parte constitutiva del hecho artístico.

Palabras clave: ASPO, Internet, Artes, Acceso abierto.

Resumo: $\mathrm{O}$ artigo reflete sobre o acesso a conteúdos culturais-artístico durante o Isolamento Social Preventivo e Compulsório organizado como estratégia para reduzir a propagação do vírus Covid-19. O texto identifica, descreve e contrasta as estratégias realizadas por plataformas comerciais de distribuição de conteúdo pela Internet e por associações culturais dependentes do Estado. Por fim, o artigo analisa duas experiências artísticas em que as arquiteturas das plataformas digitais que possibilitam a transmissão passam a ser parte constitutiva do acontecimento artístico.

Palavras-chave: Quarentena, Internet, Artes, Acesso aberto.

Abstract: The article reflects on the access to cultural-artistic content during the Preventive and Compulsory Social Isolation arranged as a strategy to reduce the spread of the Covid-19 virus. The text identifies, describes and contrasts the strategies carried out by commercial platforms that distributes content over the Internet and by cultural organizations dependent on the State. Finally, the article analyses two artistic experiences in which the architectures of the digital platforms that enable the transmission become a constitutive part of the artistic event.

Keywords: Quarantine, Internet, Arts, Open Access. 


\section{INTRODUCCIÓN: EPIDEMIAS EN UN MUNDO (HIPER)CONECTADO}

Los acontecimientos de 2020 han sido caricaturizados en numerosos memes; pero sin dudas uno de los que mejor los retrata es el que opone dos imágenes: la de la izquierda representa "mis planes" mientras que la de la derecha muestra algo inesperado que los arruina y sobre la que se lee el texto "El 2020". (Imagen 1)

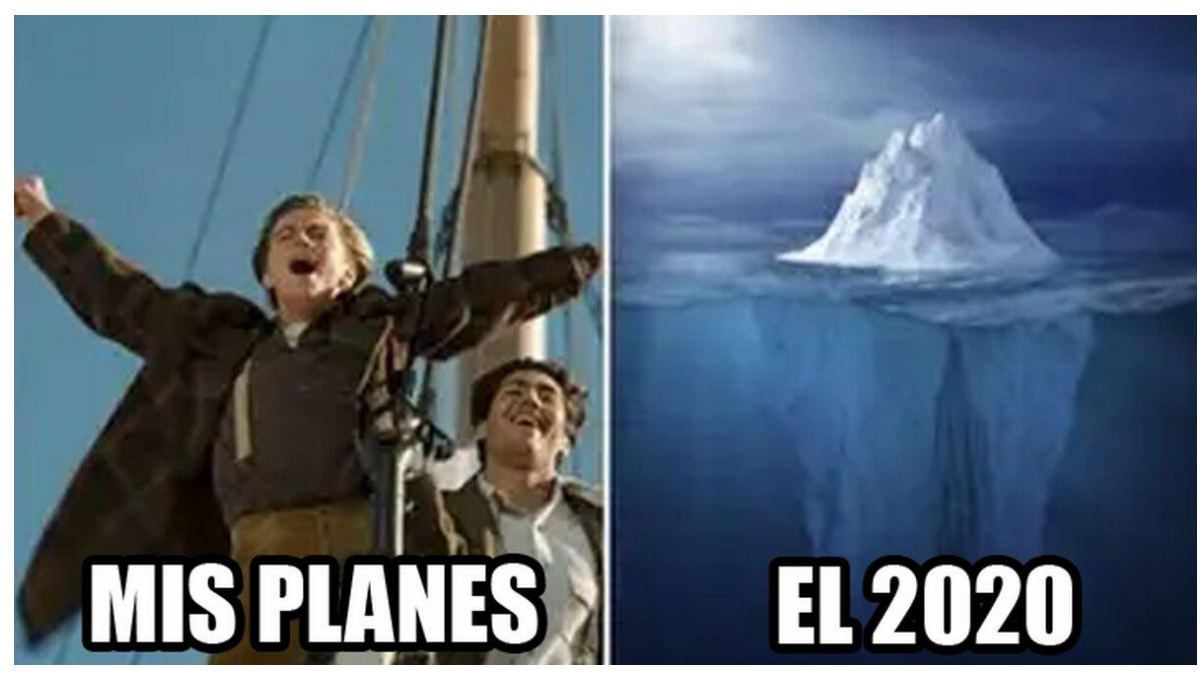

Imagen 1

Ejemplo del tipo de meme "Mis planes/El 2020"

Recuperado de https://larepublica.pe/tendencias/2020/05/22/mis-planes-2020-origen-y-de-d onde-salio-el-meme-de-mis-planes-vs-el-2020-que-es-viral-en-facebook-whatsapp-e-instagram/

Durante este año se ha desatado una de las peores pandemias de la historia, que se globalizó a la velocidad de los viajes en avión que transportan turistas, mercancías e interconectan el mundo. Los viajes siempre han trasladado las enfermedades, por ejemplo la viruela, el sarampión, el tifus, la gripe, la escarlatina, la peste bubónica, entre otras que ya tenían amplio desarrollo en Europa (Alchon, 2003) fueron traídas a América durante el largo proceso de colonización y enculturación (Martín Barbero, 1991) que sufrió el continente. La peste bubónica, antes de ser trasladada a América, había causado una de las epidemias más grandes de la historia europea. Conocida como la "peste negra” a mediados del siglo XIV se esparció por Europa, Asia y el norte de África siguiendo la ruta de la seda y provocando la muerte de la cuarta parte de la población de esos territorios (Sánchez-David, 2008). Otra epidemia recordada es la de la gripe tipo A, conocida popularmente como "gripe española", que durante la primera guerra mundial se dispersó por el traslado de tropas entre Estados Unidos y Europa. En Argentina causó cerca de 15 mil muertes (Carbonetti, 2010).

Según la Cámara Argentina de Especialidades Medicinales -CAEME- (2020) en las décadas de 1950 y 1960 se produjeron las primeras pandemias por nuevas formas de gripe que se propagaron rápidamente por el uso del avión. Por su parte, el siglo XXI ya cuenta con grandes epidemias como la del Síndrome Respiratorio Agudo Severo (SARS), la gripe Aviar, la gripe A, el Ébola, el Dengue a la que ahora se suma la pandemia por Covid-19 (CAEME, 2020) Sin embargo, ninguna de las anteriores pandemias había requerido de las medidas de aislamiento y distanciamiento social que han tenido que implementarse para reducir el contagio de este tipo de coronavirus.

El Aislamiento Social Preventivo y Obligatorio (ASPO), establecido por el decreto 297/2020, comenzó a regir el 20 de marzo y se extendió, con diferentes aperturas y excepcionalidades, hasta el 9 de noviembre cuando fue reemplazado por el Distanciamiento Social Preventivo y Obligatorio (DISPO). Fueron más de 200 días en que muchas de las actividades cotidianas empezaron a realizarse mediadas por distintos dispositivos como computadoras y celulares: trabajo, educación, compras y entretenimiento de forma remota. Más de 200 días en el que las conexiones hogareñas a la red de redes sostuvieron los vínculos. 
Si bien el virus se ha propagado tanto en los autodenominados países desarrollados como en aquellos clasificados como del tercer mundo ${ }^{1} \mathrm{y}$, dentro de cada país, ha afectado a distintos sectores de la sociedad; también ha puesto en evidencia las desigualdades en el acceso a la salud, a la vivienda, al trabajo, a la educación y a Internet. En este contexto la conexión a la Red se ha vuelto aún más importante ya que es a partir de ésta que se ha intentado continuar con actividades que antes se desarrollaban de manera presencial como la educación y la participación en lo cultural-artístico (Gómez y Racioppe, 2020).

De todos los aspectos que pueden analizarse en relación a Internet como "el único cable hacia el mundo" (Fernández y Magnani, 2020) este artículo se centrará en las posibilidades de acceder a contenidos culturalesartísticos a través de la apertura y digitalización de ciertos bienes simbólicos. También abordará algunas experiencias de acceso a espectáculos que antes se desarrollaban de manera offline y que fueron reconfiguradas a partir del aislamiento social.

\section{CATÁlogos ABIERTOS: UNA MIRADA FUgAZ A LOS CONTENIDOS PREMIUM}

Hay un tipo de meme que puede caracterizar el tema que se abordará en este trabajo ya que, aunque no se haya propagado tanto como el de "Mis planes/el 2020", sintetiza una de las ideas que se busca resaltar. El personaje de Homero Simpson sentado en el bar de Moe y alrededor de él todas las personas con la indicación de que están haciendo vivos en Instagram. (Imagen 2)

\section{Hoy cuando entré al Instagram}

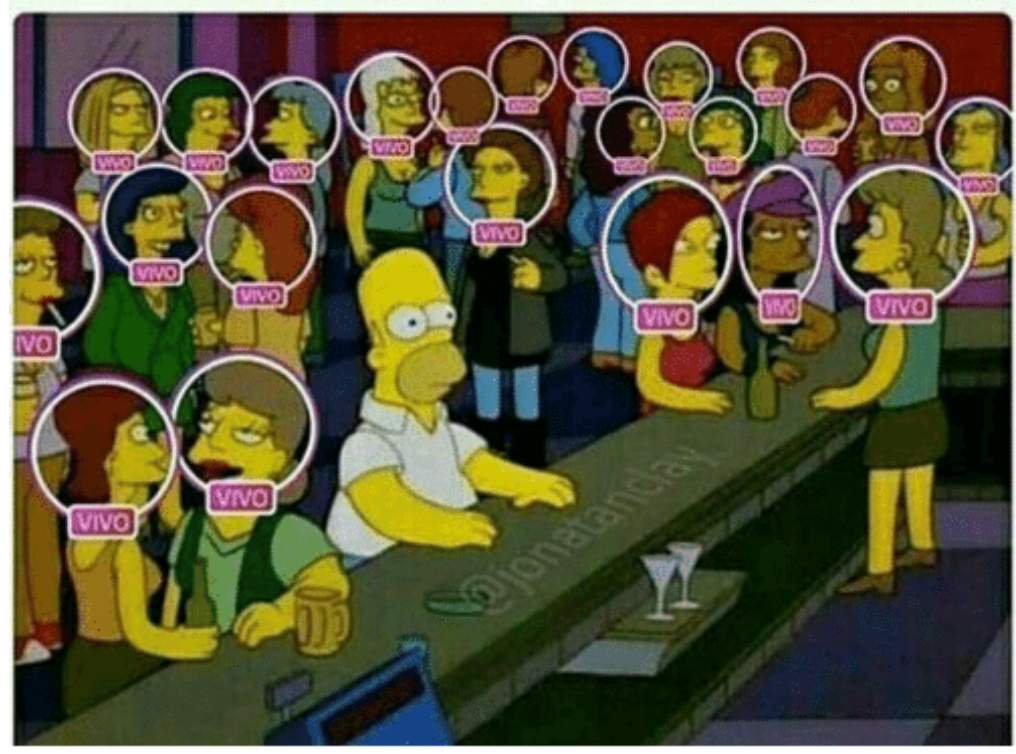

\section{"Todo el mundo en vivo" =- =-}

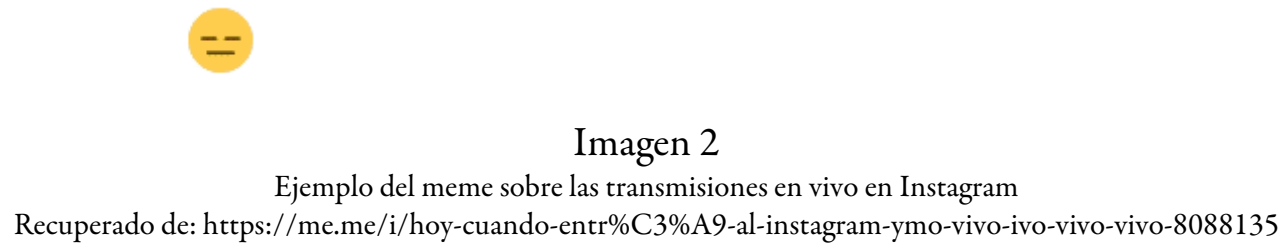

Los primeros días de ASPO en Argentina coincidieron con el de los países europeos lo que generó la sensación de ser parte de una situación global, de una suerte de distopía fílmica compartida en la que empezó a revalorizarse la creación, el intercambio y la producción colaborativa. En Italia salían a los balcones a cantar 
temas de la tradición popular y desde Argentina se miraban esas acciones en las redes sociales digitales. También se seguían los consejos que desde España publicaban para sobrellevar el encierro. En esas primeras semanas proliferaron los vivos en Instagram de influencers entrevistando a influencers, los hilos en Twitter con recomendaciones, recetas o estados de situación; los challenges en TikTok. Se produjeron y circularon gran cantidad de contenidos que surgieron, como señalan Jenkins, Ford y Green (2015), desde las grassroots, es decir no desde las grandes industrias culturales, sino desde las comunidades de usuarios/as. Propuestas lúdicas y colaborativas que hasta llevaron a iniciar un museo en Instagram, el Covid Art Museum, para compartir obras relacionadas con la situación de pandemia.

Luego, muchas plataformas anunciaron que permitirían acceso gratuito a sus contenidos para entretener a la gente y contribuir, de este modo, a que se quedaran en casa. Esta pretensión de llenar el tiempo de ocio, de generar actividades para mantenerse ocupado/a, de ser productivo/a también atravesó fuertemente las primeras épocas del ASPO.

Una de las primeras empresas en anunciar la apertura gratuita de su catálogo fue Pornhub, una plataforma de contenidos porno. Primero habilitó sus servicios para los/as usuarios/as de Italia y luego lo hizo extensivo a "todo el mundo" desde mediados de marzo y hasta mediados de abril. Algo similar ocurrió con Scribd, una plataforma de libros electrónicos, que abrió su biblioteca por un mes, entre marzo y abril. Lo significativo en el caso de Scribd es que tiene un preview en el que suscriptores/as que no pagan pueden acceder a fragmentos de documentos y libros. Además, en algunos casos, permite la descarga si el/la usuario/a sube una cantidad de archivos a la plataforma. Por lo tanto, una parte de sus contenidos se construye colaborativamente; sin embargo el acceso no se condice con esta lógica de construcción. Los/as suscriptores deben pagar en dinero para acceder al sector premium de la biblioteca digital, conformado a partir de acuerdos con diferentes editoriales. O pueden realizar una especie de intercambio subiendo a la plataforma otros archivos de texto para poder descargar un material específico. En ese aspecto $S$ cribd plantea una lógica de acceso que no aparece en otro tipo de plataformas que proveen contenidos culturales-artísticos como Netflix o Spotify, ya que éstas no solicitan a sus usuarios/as que contribuyan al catálogo, incluso cuando tienen una versión gratuita como Spotify.

En las lógicas de Scribd se ve claramente la tensión entre, por un lado, la Inteligencia Colectiva (Lévy, 2004) y la producción colaborativa de las comunidades de fans (Jenkins, 2013) y, por el otro, los modelos de negocio de las plataformas (Srnicek, 2018) ya que aquello que contribuimos a crear, luego nos es restringido. Por eso también es importante distinguir la apertura momentánea de los catálogos de la liberación de contenidos. Liberar contenidos implica ponerlos a disposición de todas las personas, sin restricciones, sin fecha de vencimiento y utilizando algún licenciamiento que permita descarga y re-distribución. Lo que hicieron estas plataformas fue una promoción de sus servicios que si bien es válida e interesante, se sigue manejando dentro de las lógicas de distribución establecidas.

En este sentido de apertura de catálogos, varias editoriales como Anagrama, Penguin Random House, Planeta, entre otras se unieron al hashtag\#YoMeQuedoEnCasaLeyendo y permitieron la descarga gratuita de algunos libros. Además, a partir de una iniciativa de la Universidad de Salamanca se creó el sitio web https://w ww.yomequedoencasaleyendo.org que organizó en colecciones los libros que distintas bibliotecas y editoriales habilitaron para ser leídos de manera gratuita. Esta página funcionó como un catálogo que hipervinculaba a los sitios en los que esos títulos se encontraban, ya fuera en bibliotecas o en librerías online. Además, dentro de esta web se creó una colección de obras literarias que ya se encuentran en dominio público y que pueden ser descargadas directamente desde https://www.yomequedoencasaleyendo.org

Excepto por los libros que están en dominio público, las otras descargas gratuitas ya no están disponibles. $\mathrm{Al}$ igual que Pornhub y Scribd la puesta en disponibilidad no fue permanente. Sin embargo, un aspecto a tener en cuenta es que fue una experiencia que se volvió colaborativa ya que distintas instituciones argentinas como editoriales universitarias e independientes compartieron materiales utilizando ese hashtag y también 
programaron charlas y ciclos de lectura a través de plataformas como YouTube o de la función de transmisión en vivo de Instagram.

Lo que tienen en común estas iniciativas es que surgieron primero para Europa y luego se hicieron extensivas a otros lugares del mundo. Estuvieron disponibles, además, durante lapsos cortos vinculados a la situación del aislamiento en los países del hemisferio norte que ingresaron al verano mientras en América del Sur empezábamos el invierno y, por lo tanto, el momento más complejo a nivel de la propagación del virus.

\section{LO PÚBLICO EN INTERNET}

El ASPO en Argentina fue más largo que el de la primera ola europea porque el virus llegó cuando era otoño, mientras que en Europa era primavera lo que les permitió iniciar una nueva normalidad durante el verano. Por lo tanto, para fines de mayo en Argentina ya se había dejado de percibir que se era parte de un destino compartido y el aislamiento empezó a sentirse como una tarea cada vez más ardua. La solidaridad empresarial de esos primeros meses se diluyó y ni Scribd, ni Pornhub, ni HBO, ni Amazon Prime nos dejaron seguir accediendo en forma gratuita a sus catálogos a pesar de que estas empresas líderes del capitalismo de plataformas (Srnicek, 2018) se configuraron como las ganadoras en la pandemia. Los servicios de contenidos por streaming como Netflix, HBO, Amazon Prime y los de comercio electrónico fueron los más beneficiados económicamente en 2020 (Jiménez, 2020).

Por eso es importante mencionar algunas experiencias regionales y nacionales que han recuperado el patrimonio cultural-artístico de bibliotecas, museos, teatros, ferias para compartirlo en distintas plataformas. Algunas de éstas fueron desarrolladas en el contexto de pandemia como por ejemplo el sitio Seguimos educando del Ministerio de Educación de la Nación Argentina en el que, además de contenidos creados especialmente para continuar con los procesos de enseñanza-aprendizaje, se comparten materiales como libros y videos en la sección biblioteca multimedia. En otros casos, las organizaciones culturales se valieron de plataformas como YouTube, Flickr y las redes sociales digitales para continuar en contacto con sus públiques.

El Museo Nacional de Bellas Artes, por ejemplo, digitalizó, produjo y subió contenidos a plataformas como YouTube y Flickr para, entre otras actividades, homenajear a León Ferrari a cien años de su nacimiento. Un homenaje y una retrospectiva que estaban pensadas para el territorio físico del museo y que fueron llevadas al territorio de lo online. En YouTube compartieron entrevistas a curadores/as, críticos/as, artistas, músicos/as y familiares de Ferrari en las que se cuentan diferentes aspectos de su vida. Además, subieron a Flickr imágenes de algunas de sus obras y distintas fotografías del artista en su taller o en situaciones de la vida cotidiana.

Otra plataforma que, si bien ya existía, se adecuó a la situación de ASPO fue la de Cine.ar Play que incorporó los "jueves de estreno" como espacio para compartir las películas del cine nacional que debían ser estrenadas en salas. A estas películas se puede acceder de manera gratuita durante la primera semana, que es la del estreno; luego continúan en el catálogo; pero se debe pagar un alquiler de 30 pesos. Además, entre el 21 y el 29 de noviembre Cine.ar Play se convirtió en la plataforma oficial del $35^{\circ}$ Festival de Cine de Mar del Plata por lo que se pudo acceder en forma gratuita y desde cualquier lugar del país a las diferentes películas que participaron de la competencia.

Por su parte, el Teatro Cervantes creó el espacio Cervantes online \#QuedateEnCasa para compartir a través del canal de YouTube obras que ya habían sido estrenadas. Los videos de estas puestas en escena estaban disponibles de manera gratuita durante 4 días, de jueves a domingo - emulando las fechas en las que generalmente hay funciones-. En la cartelera se incluyeron obras del programa federal de "Teatro Cervantes produce en el país" lo que permitió que producciones realizadas en distintas localidades argentinas se conozcan en otros territorios.

Pero además de esta programación teatral online, generaron un ciclo de conversaciones con dramaturgos/ as, directores/as, críticos/as, actores y actrices que se emitió por YouTube y que quedó disponible en ese canal. También incorporaron la sección "Detrás de escena” con videos que muestran el backstage de distintas obras. 
Un detalle interesante es que en las cuentas de sus redes sociales digitales cambiaron su nombre por "Teatro Cervantes (Desde \#)" De este modo, la situación de pandemia que obligó al cierre de los teatros posibilitó que el equipo de gestión del Cervantes empezara a construir en Internet un repositorio del patrimonio teatral argentino.

En este contexto, el Centro Cultural Kirchner incorporó al catálogo en línea y de forma permanente los registros audiovisuales de los conciertos que se realizaron durante sus cinco años de existencia. Además, en el marco del ASPO se realizaron producciones que también fueron compartidas en el canal de YouTube y en el sitio web (un ciclo virtual de artes escénicas, el festival online de Byte Footage, un registro literario de la situación de pandemia, el festival de cine Asterisco, entre otras) y se hicieron conciertos por streaming a los que se accedía de manera gratuita.

El Ministerio de Cultura de Argentina creó el sitio Compartir Cultura que, a través de distintas categorías como "música", "teatro", "literatura", "podcasts", "cine.ar", "artes visuales", permite el acceso al archivo digitalizado de las producciones realizadas por los distintos organismos dependientes del Ministerio. Este sitio funciona como un lugar de convergencia de las propuestas descriptas anteriormente lo que facilita la búsqueda al redirigir a las carteleras online de Museos, Teatros y Centros Culturales dependientes del Estado.

Estas experiencias llevadas a cabo por organizaciones estatales y, por lo tanto, públicas nos permiten reflexionar acerca de la potencialidad de los usos de las plataformas online no sólo como archivo del patrimonio, sino también como estrategia de federalización de las producciones que generalmente se desarrollan en la Ciudad Autónoma de Buenos Aires. Si bien el Estado argentino tiene distintos programas de federalización, por ejemplo a través de los espacios INCAA que exhiben películas nacionales en 68 salas distribuidas en todo el país (INCAA, 2019) o a partir del programa "Teatro Nacional ArgentinoTeatro Cervantes produce en el país" que ejecuta y financia proyectos teatrales que se desarrollan en distintas localidades de Argentina; hay una centralidad en la Ciudad Autónoma de Buenos Aires que da cuenta de las relaciones de poder geográficas y las desigualdades entre centros y periferias. Aunque esas desigualdades geográficas también se dan en las infraestructuras para el acceso a Internet, la Encuesta Nacional de Consumos Culturales de 2017 identifica que el 63,5\% de las personas encuestadas se conectan desde su casa y que el 75\% utiliza el celular para hacer consumos culturales: mirar películas, escuchar música, leer, jugar videojuegos (SInCA, 2017) Estos datos parecen indicar que la digitalización de producciones culturales-artísticas para la construcción de repositorios, la realización de streamings y la puesta a disposición de distintos materiales en plataformas de Internet permitirían una federalización y extensión de les públiques que tradicionalmente acceden a estos consumos culturales. Por lo tanto, la situación de pandemia posibilitó a los y las gestores/as culturales identificar a Internet como un escenario más de producción de lo artístico y no solamente como un espacio de difusión de actividades.

En otros países de la región se desarrollaron experiencias similares a las llevadas adelante por organismos públicos de Argentina. Según la Organización de Estados Iberoamericanos para la Educación, la Ciencia y la Cultura (OEI, 2020) en América del Sur los gobiernos de Argentina, Brasil, Chile, Colombia, Ecuador, Uruguay, Venezuela, Perú y Paraguay impulsaron propuestas culturales de acceso por Internet. En Brasil, por ejemplo, la Secretaría de Cultura de São Paulo creó \#CULTURAEMCASA una plataforma de streaming a demanda de acceso gratuito que reunió recitales, patrimonio de museos, películas y programación en vivo.

En Chile a través del sitio Elige Cultura se compartieron recorridos virtuales en $360^{\circ}$ y con audio guía del Museo Gabriela Mistral de Vicuña; del Cerro Santa Lucía, de la Casa-Museo Santa Rosa de Apoquindo entre otros espacios que conforman el patrimonio cultural de ese país. En ese sitio, además, se puede acceder a filmaciones de obras de teatro, de conciertos y también a películas. Una cartelera digital permite ver las actividades que se hacen por streaming, por ejemplo el festival Rockódromo -que desde hace más de 15 años se realiza en Valparaíso con bandas de todo el país y en 2020 se transmitió online- y los ciclos de teatro para niños/as que se llevaron a cabo en distintos momentos del aislamiento social por el Covid-19. Un 
aspecto interesante es la categoría "artesanías" que reúne conversaciones con artesanos y artesanas de distintas regiones del país.

Otro ejemplo es el del Ministerio de Cultura y Patrimonio de Ecuador que habilitó recorridos virtuales en 11 museos que geográficamente se encuentran en distintas localidades; pero que en lo online se reúnen en el sitio https://www.museos.culturaypatrimonio.gob.ec/redmuseos/ La mayoría de estos recorridos están gestionados en Poly, un software de Google que permite compartir objetos en 3D. Si bien lo más recomendable sería que el Estado tenga su propio desarrollo de software, esto implica unos costos que no siempre están disponibles; por lo que el uso de plataformas existentes para sortear la situación es una táctica interesante.

Además, el Ministerio de Cultura ecuatoriano creó el espacio "Sitios Culturales" que bajo la consigna \#QuedateEnCasa puso a disposición distintos materiales digitalizados: obras teatrales filmadas, videos de actuaciones de la compañía nacional de danza y de distintas orquestas. También permitieron el acceso a bibliotecas, repositorios de textos y a distintas películas ecuatorianas que pueden verse de manera gratuita en la plataforma.

Por su parte, el Ministerio de Turismo de Perú a través de las cuentas de Twitter, Instagram y YouTube de "VisitPeru" y "Tú, qué planes" compartió videos en $360^{\circ}$ de distintos sitios emblemáticos, challenges y diversos contenidos bajo lemas como "cuando piensas en \#volver" o "vamos a \#volver". Incluso convocaron a diferentes artistas a reversionar la canción "Cuando piensas en volver", del músico peruano Pedro SuárezVértiz, que se convirtió en el slogan de las publicaciones sobre turismo durante la pandemia. En el marco de estas actividades de "Descubrir Perú desde casa" el $1^{\circ}$ de noviembre transmitieron por Facebook Live la reapertura del Machu Pichu tras el cierre por la pandemia.

Estas actividades brindadas desde los Estados de la región permiten acceder al patrimonio cultural de los distintos países que incluyen no sólo el repertorio más clásico de museos, orquestas y ballets nacionales; sino también contenidos que podríamos pensar como populares y que van desde las artesanías, los festivales de música, las obras de teatro y las películas del circuito independiente hasta el recorrido con fotos o con videos en $360^{\circ}$ por diferentes localidades para conocer sus tradiciones.

\section{INTERNET COMO ESCENARIO/INTERNET COMO ESTÉTICA}

Para cerrar este artículo quisiera mencionar dos experiencias que se desarrollaron en pandemia a través de plataformas que permiten la transmisión sincrónica. Una de ellas es la Performance In-Cierta realizada por Julieta Caputo y Bárbara Sánchez, basada en los textos del libro Bocacalles publicado por Paloma Sánchez. El ciclo constó de 5 episodios que fueron transmitidos por Zoom, uno por día, del 3 al 7 de agosto. Tienen una duración de entre cinco y nueve minutos y se pueden mirar de manera independiente, en cualquier orden, ya que lo que los une es el libro de poemas, la perspectiva feminista y el haber sido puestos en escena en el contexto de ASPO. La propuesta fue una de las premiadas por el Concurso Nacional de Actividades Performáticas en Entornos Virtuales llevado adelante por el Instituto Nacional del Teatro con el propósito de fomentar actividades escénicas en el contexto de pandemia.

Más allá de la transmisión en vivo, esas performances fueron grabadas y ahora se encuentran disponibles en YouTube. Lo interesante es que en esas grabaciones aparece centralmente el dispositivo utilizado para su transmisión que es, también, parte de la puesta: las múltiples ventanas que muestran los rostros de los y las espectadores/as, el chat al costado de la pantalla o emergiendo como un mensaje push, los íconos del menú de la plataforma que se conjugan con la puesta en escena en las casas de las performers y con imágenes digitales que se muestran a partir de la opción de compartir pantalla.

Al final de cada video se lee "Bariloche - Capital Federal - La Plata" que son los tres lugares desde los que se crea la performance, ya que una de las performers actúa desde Bariloche, la otra desde CABA y la autora de los textos vive en La Plata. Tres puntos geográficos que convergen en esa sala de Zoom que es el escenario, 
el encuadre, pero también parte de lo que se relata. Luego de los títulos y los agradecimientos típicos del final de una puesta audiovisual, en la pantalla aparece el botón de "End Meeting" que es el que permite cerrar la videoconferencia. De este modo, la lógica de las conexiones por Internet vuelve a introducirse en la narrativa. La obra termina cuando se termina el (ciber)encuentro.

Otra experiencia que se realizó en pandemia - con convocatorias a artistas de un circuito mainstreamfue el festival \#ArgentinaEnLaCasa impulsado por Billboard Argentina y Unidxs por la música. Tenía como propósito recaudar fondos para ayudar al personal técnico que trabaja de montar recitales en vivo como los/ as iluminadores/as, los/as sonidistas y el personal de carga. La recaudación se hacía de dos maneras: a través de una tienda online en la que se ofrecían productos donados por los y las artistas (vinilos, vestuario de recitales, pósters de promoción de eventos, instrumentos musicales, etc) y a través de mensajes auspiciados en el chat del YouTube de la transmisión en directo.

El festival se desarrolló durante 24 horas el 9 de julio y contó con la participación de bandas y cantantes de distintos géneros musicales, algunos/as de ellos/as muy reconocidos/as mediáticamente como Abel Pintos, David Lebón, Kevin Johansen, Los Palmera, Rosario Ortega, Sandra Mihanovich, Tini, Soledad, entre otros/ as. El evento se realizó en el canal de YouTube de Billboard Argentina y el acceso fue gratuito.

Uno de los aspectos interesantes fue la estética que se construyó a partir de mostrar varias ventanas en las que aparecían los/as distintos/as artistas. En ese momento aún no estaban autorizados los streamings desde teatros o salas de concierto, por lo que los y las músicos/as tocaban desde la intimidad de sus hogares y no podían juntarse, al menos en la zona del AMBA, con los/as otros/as músicos/as. Esta restricción impedía el tipo de streaming al que nos hemos acostumbrado en estos últimos meses en los que las bandas montan un show de manera conjunta en un escenario, aunque sin público presencial.

Esta restricción significó un desafío para el desarrollo del evento que se resolvió retomando la estética de las ventanas y las pantallas divididas. Si bien en el caso de los y las solistas la participación se realizó como un acústico (por lo que sólo requerían aparecer ellos/as en pantalla), en el caso de los grupos musicales cada integrante tocaba su instrumento desde su casa y la agrupación se formaba en la pantalla a partir de la yuxtaposición de las múltiples ventanas. Las participaciones fueron grabadas con anterioridad, lo que posibilitó la edición de imagen y sonido; pero, más allá de esto, se configuró una estética anclada en la lógica de encuadre de Internet en la que, según Boris Groys (2016, p. 198), el marco siempre está presente.

A esto se le sumaron los planos pecho o primeros planos, los fondos hogareños de bibliotecas, sofás o ventanas y el registro desde una cámara fija que es propio de las gramáticas de YouTube (ya que es el modo más extendido de toma de imagen entre los/as youtubers). Además, si se accedía desde YouTube web -y no desde la aplicación- aparecía el chat con las conversaciones de las personas conectadas al evento, lo que sumaba otro elemento a esa puesta en escena.

Estos dos ejemplos, entre los cientos que se dieron en el contexto de ASPO, permiten identificar unas lógicas de producir y también de mirar que retoman estéticas a las que nos han acostumbrado tecnologías como la computadora, el celular y, principalmente, la conexión a Internet. Les públiques participando desde la multitarea de escuchar, mirar, comentar en el chat y, seguramente, realizar al mismo tiempo otras actividades ajenas a esa experiencia. La práctica de ser audiencia desde un montaje blando, como lo denomina Harun Farocki; pero que incluso va más allá del planteo del autor quien se refería a les públiques que construían la obra a partir de recuperar fragmentos de audiovisuales transmitidos en distintas pantallas de forma simultánea (2013, p. 285). En esos casos, el montaje para Farocki (2013) se completaba en la mente de los/as espectadores/as, tal como para Henry Jenkins (2008) se da la convergencia cultural.

En estos dos ejemplos, además de ese montaje blando (Farocki, 2013), se produce una mixtura del arte con la vida de una manera más profunda de lo que pudieron haber imaginado las vanguardias y las neovanguardias porque lo artístico no sólo llega a los hogares a través de las pantallas, sino que se produce desde los hogares. Las y los artistas cantan y ejecutan instrumentos desde la intimidad de sus livings; las performers utilizan sus propios muebles, la propia vista desde sus ventanas para construir la escena. En estas y otras experiencias de 
los tiempos del ASPO hay una articulación de intimidades, de cotidianidades que quizás no vuelva a repetirse luego de la pandemia. De hecho la habilitación del streaming desde salas de teatro y de conciertos ya diluyó esa práctica que, aparentemente, seguirá relegada a las producciones de youtubers e instagramers.

\section{A MODO DE CIERRE}

Este artículo se presenta como una exploración de diferentes casos que permiten identificar algunas características de la circulación de lo cultural-artístico durante el Aislamiento Social Preventivo y Obligatorio (ASPO) establecido para disminuir la propagación del Covid-19. Para esto se retoman, en primer lugar, estrategias de empresas que llevan varios años distribuyendo contenidos por Internet como Pornhub y Scribd que, en un momento del aislamiento, decidieron solidarizarse y abrir temporalmente sus contenidos premium. De este modo, permitieron que tengamos un pantallazo fugaz de lo que significa el acceso de pago. Como señalábamos, no se trata de una liberación de materiales ni de acceso abierto, sino de una promoción temporal que sirve, también, de estrategia de venta y posicionamiento.

Luego, el artículo recupera experiencias llevadas adelante por el Estado argentino y por algunos Estados de otros países latinoamericanos. En este punto aparece una estrategia que puede leerse desde el acceso abierto y desde la preservación y la construcción de una memoria nacional de lo cultural-artístico. Estas propuestas son interesantes por varios motivos: permiten conexión entre distintos puntos dentro de cada país y también entre países, facilitan la distribución federal de obras que se exhiben o ejecutan en las grandes ciudades, al mismo tiempo que posibilitan recuperar experiencias de otras regiones que muchas veces se desconocen desde la centralidad de las capitales (las entrevistas a artesanos/as que compartieron en la plataforma "Elige Cultura" del gobierno de Chile, la exhibición por YouTube de obras que integran el programa "El Cervantes produce en el país", entre otras) y contribuyen a construir un repositorio de los acervos culturales latinoamericanos.

Podríamos sostener que las decisiones políticas tomadas durante esta pandemia aceleraron los procesos de digitalización del patrimonio que venían realizando distintas organizaciones culturales. Ciertamente queda mucho por hacer en ese sentido; pero es claro que desde los Estados se comprendió la importancia de compartir lo cultural-artístico también en lo online. Además, se ha hecho uso de distintas plataformas digitales para producir nuevos contenidos: ciclos de charlas por Zoom; conciertos, obras teatrales y danzas por streaming; entrevistas en Instagram que pasan a formar parte de ese acervo con el agregado de ser testimonios del contexto de pandemia.

Por último, se recuperan dos experiencias, entre muchas de las que se dieron durante el ASPO, para analizar cómo las arquitecturas de las plataformas utilizadas para su puesta en escena se entraman con las estéticas y las narrativas de esas producciones. En ambas los entornos digitales por los que se transmiten no son asumidos como transparentes, sino que, por el contrario, se insertan de manera consciente en el hecho artístico, posicionando a les públiques en una situación que se entiende como diferente de la que se tiene en un teatro, un centro cultural o una sala de conciertos.

Lo destacable de éstas y otras propuestas que se han desarrollado en la digitalidad durante la pandemia es que han comprendido que su identidad está en construcción y que, por lo tanto, no pueden ser configuradas desde las mismas lógicas que las puestas en escena de lo offline. ¿Se constituirán como géneros o formatos independientes e identificables? ¿Continuarán luego de terminada la pandemia o serán sólo una marca en un momento de las historias de las producciones artísticas? Son preguntas que todavía no tienen respuestas; pero que interpelan a identificar los diferentes hechos artísticos que se construyen como testimonio de este contexto histórico. 


\section{REFERENCIAS}

Alchon, S. (2003). A pest in the land: New World Epidemics in a Global Perspective. Albuquerque : University of New Mexico Press. Recuperado de https://books.google.com.ar/books?id=YiHHnV08ebkC\&printsec=copyright\& redir_esc $=\mathrm{y} \# \mathrm{v}=$ onepage\& $\mathrm{q}=\mathrm{scarlet} \% 20 \mathrm{fever} \& \mathrm{f}=$ false

Cámara Argentina de Especialidades Medicinales - CAEME. (2020). Otras pandemias que afectaron a la Argentina. Recuperado de https://www.caeme.org.ar/otras-pandemias-que-afectaron-a-la-argentina/

Carbonetti, A. (2010). Historia de una epidemia olvidada. La pandemia de gripe española en la Argentina, 1918-1919. Desacatos, (32), pp. 159-174. Recuperado de http://www.scielo.org.mx/scielo.php?script=sci_arttext\&pid=S1 607-050X2010000100012\&lng=es\&tlng=es

Farocki, H. (2013). Desconfiar de las imágenes. Ciudad Autónoma de Buenos Aires : Caja Negra.

Fernández, E. y Magnani, E. (2020). Infancias, plataformas y cuarentena. El único cable hacia el mundo. Anfibia. Universidad Nacional de San Martín. Recuperado de http://revistaanfibia.com/ensayo/unico-cable-hacia-mu ndo/

Gómez, L. y Racioppe, B. (2020). Experiencias del presente, imágenes del futuro. Una reflexión inicial sobre el arte y las tecnologías en tiempos de pandemia. Cuadernos del pensamiento crítico latinoamericano. CLACSO.

Groys, B. (2016). Arte en flujo. Ensayos sobre la evanescencia del presente. Ciudad Autónoma Buenos Aires : Caja Negra.

INCAA (2019). “Memoria de gestión 2017-2019”. Recuperado de http://www.incaa.gov.ar/wp-content/uploads/2 019/12/INCAA1719.pdf

Jenkins, H. (2008). Convergence Culture. La cultura de la convergencia de los medios de comunicación. Ciudad Autónoma Buenos Aires : Paidós.

Jenkins, H. (2013). Fans, blogueros y videojuegos. La cultura de la colaboración. Ciudad Autónoma Buenos Aires : Paidós.

Jenkins, H., Ford, S. y Green, J. (2015). Cultura transmedia. La creación de contenido y valor en una cultura en red. Barcelona : Gedisa.

Jiménez, M. (2020). “Los ganadores empresariales de la pandemia son tecnológicos”. Cinco Días, El País Economía. Recuperado de https://cincodias.elpais.com/cincodias/2020/04/26/companias/1587926357_776058.html

Lévy, P. (2004). Inteligencia Colectiva: por una antropología del ciberespacio. Washington, DC : Organización Panamericana de la Salud. Recuperado de: http://inteligenciacolectiva.bvsalud.org/public/documents/pdf/es/ inteligenciaColectiva.pdf

Martín-Barbero, J.(1991). De los medios a las mediaciones. Comunicación, cultura y hegemonía. México : Ediciones Gili.

Organización de Estados Iberoamericanos. (2020). "Iniciativas culturales destacadas impulsadas en los países con motivo de la pandemia y la cuarentena”. Recuperado de https://www.oei.es/cultura-covid-19/iniciativas

Sánchez-David, C. (2008). La muerte negra. "El avance de la peste”. Revista Med, 16(1), pp. 133-135.

Sistema de Información Cultural de la Argentina (2017). Encuesta Nacional de Consumos Culturales. Recuperado de https://www.sinca.gob.ar/Encuestas.aspx

Srnicek, N. (2018). Capitalismo de plataformas. Ciudad Autónoma Buenos Aires : Caja Negra.

\section{Notas}

1 Es importante señalar que hasta el momento el virus no ha tenido gran propagación en África. 